\title{
Peran Bahasa Arab dalam Menghadapi Paradigma Pendidikan Di Indonesia Era Society 5.0
}

\author{
1Mahdir Muhammad, ${ }^{2}$ Cahya Edi Setyawan \\ 1IAI Al Aziziyah Aceh, ${ }^{2}$ STAI Masjid Syuhada Yogyakarta \\ E-mail: abutiro@gmail.com, cahya.edi24@gmail.com
}

Tanggal Submitt: 04/11/2021 Tanggal diterima: 06/11/2021 Tanggal Terbit: 25/12/2021

$$
\begin{aligned}
& \text { ملخّص:إن ظهور } \\
& \text { الشخصية و تأثير التكنولوجيا ليس بالضرورة أن يكون له تأثير إيجابي على عالم التعليم في } \\
& \text { إندونيسيا. شهد النموذج التربوي تحولا كبيرا في نموذج الاتحاه ونموذج التفاعل التربوي والوسائط } \\
& \text { التعليمية. في الوقت نفسه، اللغة العربية حاضرة في المجتمع كإبتحاه في عصر المجتمع وتلعب دورًا } \\
& \text { مهمًا في مواجهة شخصية وتطور الحضارة في إندونيسيا في بجال التعليم. دور اللغة العربية هو } \\
& \text { كأداة وموضوع ومهمة خاصة في إندونيسيا. تلعب اللغة العربية دورًا مهمًا في جميع المجالات بما } \\
& \text { في ذلك المجالات السياسية والاقتصادية والاجتماعية للمجتمع الإندونيسي. كل هذه المجالات } \\
& \text { تبدأ من عالم تعليم اللغة العربية. تقدم هذه المقالة لمحة عامة عن المعلومات المتعلقة بدور اللغة } \\
& \text { العربية في التعليم في إندونيسيا ودورها. } \\
& \text { كلمات مفتاحية: العصر المجتمعي } 5.0 \text { ، اللغة العربية }
\end{aligned}
$$

\section{PENDAHULUAN}

Munculnya Era Society 5.0 yang dipelopori negara Jepang tahun 2019 berdampak besar pada dunia pendidikan. Perkembangan tegnologi berbasis digital menggerus arus interaksi sosial dunia nyata sehingga interaksi sosial cukup melalui digital. Karakter sosial dan kemanusiaan bergeser ke dalam dunia maya. Arus interaksi sosial mempengaruhi bidang pendidikan sehingga pada dunia pendidikan bisa dilakukan cukup dengan dalam jaringan (DARING). Era Society 5.0 dibuat sebagai antisipasi dari gejolak disrupsi akibat revolusi industri 4.0, yang menyebabkan ketidakpastian yang kompleks dan ambigu (VUCA). Dikhawatirkan invansi tersebut dapat menggerus nilainilai karakter kemanusiaan yang dipertahankan selama ini.

Era Society 5.0 mempengaruhi paradigma pendidikan di Indonesia. Pengaruh itu berdampak besar pada sumber daya manusia dan sarana pendidikan. Dengan adanya Era Society ini, secara otomatis sumber daya manusia harus di upgrade kompetensinya dalam berliterasi, bertegnologi dan lebih profesional. Kompetensi 
softskill dan hardskill menjadi fokus utama untuk di kembangkan. Guru tidak hanya mampu menguasai materi, mengkondisikan kelas, naun juga harus mampu membangkitkan semangat siswa untuk belajar, menjadi role mode, serta menguasai tegnologi dengan standar minimal mampu mengaplikasikan tegnologi dalam mengajar. Softskill guru berupa karakter pendidik yang bagus, berkahlak akrimah, sabar dan visioner untuk menjadi pendidik.

Hardskill adalah hal-hal yang berhubungan dengan profesionalitas guru dalam mengajar. Hal-hal tersebut terkait dengan kemapuan penguasaan materi, kemampuan mengkondisikan kelas, strategi mengajar, administrasi pembelajaran dan profesionalitas guru berkompeten.

Perubahan karakter dan gaya belajar generasi/pembelajar di Era Society juga akibat dapak kemajuan tegnologi. Siswa lebih cenderung menyukai gaya belajar instan, mencatat materi dengan cara memfoto di papan tulis, mencari materi menggunakan gadget, belajar cukup menggunakan komputer dan media internet. Apa yang di sampaikan guru dikelas jarang ditulis ataupun didokumentasikan dalam buku mereka.

Generasi Era Society 5.0 juga lebih menyukai menyelesaikan beberapa pekerjaan dalam satu waktu. Di samping mereka berimteraksi dalamm media sosial membahas perkembangan terkini, mereka sekali waktu juga belajar materi-materi sekolah. Inilah generasi Era Society, lebih smart dan brilian dalam belajar dan berinteraksi sosial dalam waktu sekaligus. Seiring dengan ini, pemerintah Indonesia mencanangkan model belajar dan pendidkikan dengan model konsep kemerdekaan belajar.

Belajar sudah tidak terikat dengan ruang dan waktu, bertatap muka, belajar hanya dengan buku, belajar hanya mendengarkan guru bercerita dalam menjelaskan materi, naun lebih dari itu siswa lebih menyukai belajar berbasis diskursus problematika kehidupan, berbasis kegiatan dan proyek, serta lebih otentik menganalisis kehidupan nyata menjadi bidang dan materi yang mereka diskusikan dalam proses beajar dan pembelajaran. Siswa juga diberi kemudahan dalam mengakses materi di dala platform digital seperti google classroom dll. Siswa dipermudah dengan belajar cukup menggunakan WAG, instagram, line dsb serta belajar cukup dengan tutorial saja.

Dalam dunia studi islam dan pendidikan Islam, Bahasa Arab menjadi penting, karena dengan bahasa Arab siswa dapat mempelajari materi-materi yang di dapatkan dari buku-buku berbahasa Arab. Bahasa Arab merupakan alat untuk mempermudah mereka mempelajari materi dan mengakses pengetahuan dan ilmu. Bahasa Arab berdampak besar pada pergerakan pendidikan di Indonesia. Bahasa Arab menjadi trend kekinian generasi Islam saat ini di Era Society. Bahasa Arab yan dulu hanya 
merupakan bahasa yang sekedar mempelajari Imu Agama Islam namun sekarang bahasa Arab sudah menjadi bahasa yang dipelajajri untuk urusan dunia, pekerjaan, dan misi tertentu. Dengan bahasa Arab, manusia lebih beradap, lebih sejahtera hidup di masyakarat dan lebih mampu untuk berkembangkarier serta bertahan hidup di masyakarat. Maka dari itu, penulis ingin memaparkan bagaimana peran bahasa Arab di Era Sosiety 5.0 dalam paradigma pendidikan di Indonesia khususnya di perguruan tinggi.

\section{PEMBAHASAN}

\section{Paradigma Era Society 5.0}

Society 5.0 adalah masyarakat yang dapat menyelesaikan berbagai tantangan dan permasalahan sosial dengan memanfaatkan berbagai inovasi yang lahir di era Revolusi industri 4.0 seperti Internet on Things (internet untuk segala sesuatu), Artificial Intelligence (kecerdasan buatan), Big Data (data dalam jumlah besar), dan robot untuk meningkatkan kualitas hidup manusia. ${ }^{1}$ Society 5.0 juga dapat diartikan sebagai sebuah konsep masyarakat yang berpusat pada manusia dan berbasis teknologi. Untuk mengenal konsep Society 5.0 perlu kiranya mengetahui perkembangan Society sejak dahulu, yaitu Society 1.0 manusia masih berada di era berburu dan mengenal tulisan, Society 2.0 era pertanian dimana manusia sudah mengenal bercocok tanam, Society 3.0 memasuki era industry yaitu manusia sudah mulai menggunakan mesin untuk membantu aktivitas sehari-hari, Society 4.0 manusia sudah mengenal computer hingga internet, Society 5.0 teknologi adalah bagian dari manusia itu sendiri, internet bukan hanya digunakan untuk sekedar berbagi informasi melainkan untuk menjalani kehidupan.

Society 5.0 adalah suatu konsep masyarakat yang berpusat pada manusia (human-centered) dan berbasis teknologi (technology based). Inovasi dalam Society 5.0 akan mencapai masyarakat berwawasan ke depan yang memecah rasa stagnasi yang ada. Masyarakat yang anggotanya saling menghormati satu sama lain, dan masyarakat di mana setiap orang dapat memimpin kehidupan yang aktif dan menyenangkan. ${ }^{2}$ Perbedaan antara Society 4.0 dan Society 5.0 yaitu bahwa Era Society 4.0 orang mengakses layanan cloud (database) di dunia maya melalui internet dan mencari, mengambil, dan menganalisis informasi atau data. Sementara itu, di Society

\footnotetext{
${ }^{1}$ Deguchi A.C Hirai, H Matsuoka, T. Nakano, K Oshima, M. Tai, and S Tani, Society 5.0, Chapter 1 In Hitachi-University Of Tokyo Laboratory (H.U Tokyo Lab), Society 5.0 A People-Centric Super-Smart Society, Spinger Open 2020, ISBN 978-981-15-2989-4

2 Melinda Rahmawati, Ahmad Ruslan, Desvian Bandarsyah, The Era Of Society 5.0 As the Unifacation Of Humans and Tegchnology: A Literature Review On Materialsm and Existentialism, Jurnal Dialektika, vol. 16 No.2 (2021), h. 151-162
} 
5.0, sejumlah besar informasi dari sensor di ruang fisik terakumulasi di dunia maya. Di dunia maya, data besar ini dianalisis oleh kecerdasan buatan atau artificial intelligence (AI), dan hasil analisisnya diumpankan kembali ke manusia dalam ruang fisik dalam berbagai bentuk. Di Era Society 4.0, praktik umum adalah mengumpulkan informasi melalui jaringan dan menganalisisnya oleh manusia. Namun, dalam Society 5.0, orang, benda, dan sistem semuanya terhubung di dunia maya dan hasil optimal yang diperoleh oleh AI melebihi kemampuan manusia diberi feedback ke ruang fisik. Proses ini membawa nilai baru bagi industri dan masyarakat dengan cara yang sebelumnya tidak mungkin.

\section{Paradigma Pendidikan Indonesia di Era Society 5.0}

Pendidikan dalam konteks Micro yaitu melayani kepentingan anak didik melalui proses interaksi pendidikan. Dalam konteks Macro yaitu melayani kepentingan masayarakat (bangsa, negara, dunia). Hubungan pendidikan dengan masyarakat mencakup hubungan perubahan sosial, tatanan ekonomi, politik, dan negara. Oleh karena itu, pendidikan harus bisa menjawab tantangan perkembangan zaman dengan memegang prinsip tujuan pendidikan di Indonesia. Hal ini diakibatkan dari perkembangan zaman dan tegnologi sehingga menjadikan masalah dalam pendidikan menjadi semakin kompleks.

Dunia belum lama dikenalkan dan berinteraksi dengan paradigma society 4.0 dan sekarang sudah dikenalkan dengan era baru Society 5.0 oleh jepang.. Hal ini tentu berdampak pada berbagai berbagai bidang, seperti: ekonomi, sosial, budaya hingga pendidikan. Tapaknya diskursus tentang era industri 4.0 belum kelar, bahkan di Negara Indonesia belum ada perubahan nyata. Sementara itu, Society 5.0 sudah dikenalkan Jepang. Hal ini menjadi tantangan bagi bangsa Indonesia untuk dapat menyesuaikan perkembangan teknologi yang sangat pesat. Melalui dunia pendidikan, permasalahan-permasalahan yang terus membelenggu bangsa ini agar segera diselesaikan sehingga pemerintah bisa totalitas dalam menyambut datangnya era society 5.0.

Untuk menuju era society 5.0 dalam dunia pendidikan, kita perlu memahami terlebih dahulu paradigma pendidikan di Indonesia. Adapun paradigma pendidikan dibagi menjadi dua:

1. Paradigma liberal.

Merupakan suatu proses pendidikan yang selalu berusaha untuk menyesuaikan pendidikan dengan keadaan ekonomi dan politik di luar dunia pendidikan, dengan 
jalan memecahkan berbagai masalah yang ada dalam pendidikan dengan usaha reformasi. ${ }^{3}$

2. Paradigma radikal.

Merupakan arena perjuangan politik yang menghendaki adanya perubahan struktur secara fundamental, terutama dalam politik dan ekonomi masyarakat di mana pendidikan berada. Namun, dengan kehadiran paradigma baru bukan berarti sesuatu yang tidak membawa dampak negatif, justru ini menjadi beban bagi seluruh pengisi negara ini

Menuju paradigma baru pendidikan menuju Society 5.0 membutuhkan regulasi yang jelas dan konkret sehingga tidak menimbulkan multi tafsir dalam mengimplementasikannya. Hal ini tentu akan melibatkan berbagai bidang keilmuan untuk merancang paradigma baru tersebut yang tetap mengedepankan pendidikan karakter. Selain merancang paradigma baru, tantangan lain yang selalu membelenggu ialah perberdayaan sumber daya manusia yang belum maksimal. Sebab strategi perubahan pendidikan harus dilakukan dengan perubahan pola pikir para pelaku pendidikan, di mana para pendidik harus mampu membelajarkan para peserta didik, bukan sekadar mengajari dan melatih mereka. Membelajarkan peserta didik jauh lebih sulit daripada sekadar mengajari dan melatih mereka karena harus bersifat individual, tidak dapat dilakukan secara masif, dan penuh dengan variasi keberagaman. Paradigma lama pendidikan harus diubah dengan paradigma baru yang mengutamakan kemampukan berpikir kritis dan belajar sepanjang hayat, serta selalu berinovasi menuju society 5.0 dengan tetap memegang prinsip tujuan pendidikan.

Pendidikan memiliki peran penting untuk mempersiapkan masyarakat dalam menghadapi Society 5.0. Dalam forum ekonomi dunia, telah dirumuskan bahwa terdapat sepuluh kemampuan dengan tiga diantaranya adalah kemampuan utama yang harus dimiliki manusia dalam menghadapi Smart Society. Tiga kemampuan utama tersebut diantaranya yaitu kemampuan dalam memecahkan masalah yang kompleks, kemampuan untuk bisa berpikir secara kritis, dan kemampuan untuk berkreativitas. Salah sau kemampuan yang dirasa mulai menghilang dari tahun ke tahun yaitu kemampuan dalam mendengar secara aktif menjadi salah satu kemampuan dari sepuluh kemampuan utama. Pendidikan memiliki tanggung jawab dalam memenuhi tiga kemampuan utama yang dibutuhkan dalam menghadapi masa depan. 4

${ }^{3}$ Nyong Eka Teguh Iman Santosa, Epistemologi Partisan Pendidikan Liberal, Adabiyah Jurnal Pendidikan Islam Volume 1, Nomor 1, September 2015, h. 2-15

${ }^{4}$ Herli Rohim, Darwanto, Pendidikan Untuk Menyambut Masyarakat 5.0, Prosiding Seminar Nasional Pendidikan Program Pascasarjana Universitas PGRI Palembang, 10 Januari 2020, h. 2-7 
Anak-anak tidak hanya dibekali oleh ilmu pengetahuan namun juga harus dibekali dengan cara berpikir. Cara berpikir harus mulai dikenalkan dan dibiasakan mulai dari anak-anak agar nantinya terbiasa untuk bisa berpikir secara kritis, analitis, dan kreatif. Cara berpikir ini dikenal dengan High Other Thinking Skills atau cara berpikir tingkat tinggi. Dengan memiliki kemampuan HOTS, peserta didik diharapkan dapat menemukan konsep pengetahuan yang tepat dengan berbasiskan kegiatan. Dengan begitu, peserta didik didorong untuk bisa berpikir secara kritis dan kreatif. Beberapa model pembelajaran bisa dipilih dan diterapkan oleh guru kepada peserta didik untuk mengembangkan nalar kritis peserta didik misalnya seperti: inquiry learning, discovery learning, project based learnin, problem based learning.

Dalam membiasakan kemampuan HOTS kepada peserta didik, pengajar juga perlu mengenalkan dan memberikan perasaan secara langsung di dunia nyata. Dengan begitu, peserta didik bisa memahami permasalahan yang ada di sekitar lingkungannya. Selain itu, dengan adanya dan diterapkannya konsep-konsep pembelajaran, diharapkan peserta didik dapat memahami bagaimana menyelesaikan permasalahan-permasalahan yang ada. Pengajar memiliki peran yang penting pada peserta didik yaitu bagaimana pengajar dapat memberikan arahan kepada peserta didik dalam menemukan titik permasalahan dengan solusinya.

Solusi yang diarahkan oleh pengajar, diharapkan pula tidak hanya solusi yang sudah ada lalu dipakai namun solusi dengan kebaruan seperti masalah yang baru juga sehingga peserta didik bisa berinovasi dan berkreatifitas. Pengenalan permasalahan kepada peserta didik pun tidak hanya permasalahan yang ada pada lingkungan sekitar namun juga pengenalan masalah secara universal. Sehingga akan meningkatkan wawasan dari peserta didik itu sendiri. Pemanfaatan berbagai macam teknologi seperti telepon genggam, laptop dan sebagainya juga bisa digunakan dalam pembelajaran. Dengan adanya koneksi internet yang mendukung keberadaan teknologi memungkinkan pengajar dan peserta didik mencari bahan ajar, diskusi ataupun pembelajaran melalui video dengan mengakses berbagai situs yang tersedia secara gratis. Dalam penggunaan teknologi, siapa saja bisa menggunakannya namun harus bisa memberikan makna yang positif bagi pengguna terkhusus peserta didik dalam proses pembelajaran. ${ }^{5}$

Society 5.0. Fokus keahlian bidang pendidikan abad 21 saat ini meliputi cretivity, critical thingking, communicaion dan collaboration atau yang dikenal dengan 4Cs (Risdianto, 2019). Beberapa kemampuan yang harus dimiliki di abad 21 ini meliputi : leadership, digital literacy, communication, emotional intelligence, enterpreneurship,

${ }^{5}$ Faulinda Eli Nastiti, Aghni Rizqi Ni'mal 'Abdu, Kesiapan Pendidikan Indonesia Menghadapi Era Society 5.0, Edcomtech Volume 5, No 1, April 2020,h. 2-6 
global citizenship, problem solving, team-working. Pendidikan di Indonesia untuk menghadapi society 5.0 yaitu:

1. Segi infrastruktur.

Pemerintah harus berusaha untuk meningkatkan pemerataan pembangunan dan perluasan koneksi internet ke semua wilayah Indonesi, karena seperti yang kita ketahui bahwa saat ini belum semua wilayah Indonesia dapat terhubung dengan koneksi internet.

2. Segi Sumber Daya Manusia

Sumber Daya Manusia yang bertindak sebagai pengajar harus memiliki keterampilan dibidang digital dan berfikir kreatif. Menurut Zulkifar Alimuddin, Director of Hafecs (Highly Functioning Education Consulting Services) menilai di era masyarakat 5.0 (society 5.0 ) guru dituntut untuk lebih inovatif dan dinamis dalam mengajar di kelas (Alimuddin, 2019)

3. Singkronisasi Pendidikan dan Industri

Pemerintah harus bisa menyinkronkan antara pendidikan dan industri agar nantinya lulusan dari perguruan tinggi maupun sekolah dapat bekerja sesuai dengan bidangnya dan sesuai dengan kriteria yang dibutuhkan oleh industri sehingga nantinya dapat menekan angka pengangguran di Indonesia.

4. Penerapkan teknologi sebagai alat kegiatan belajar - mengajar.

Teknologi merupakan formula pembeda yang digunakan untuk model belajar saat ini. Bagaimana siswa tidak hanya belajar tatap muka, naun juga melalui tegnologi agar bisa mengakses materi dengan sendiri. Teknologi 3D pada Augmented Reality membuat pemakainya merasakan simulasi digital, layaknya kegiatan fisik nyata. Misalkan pada simulasi pesawat terbang yang digunakan oleh para siswa penerbangan untuk lolos uji coba, sebelum melakukan praktik terbang langsung dengan pesawat sebenarnya.

Pemanfaatan Artifical Intelligence (AI) dalam dunia pendidikan untuk mengetahui serta mengidentifikasi kebutuhan pembelajaran yang dibutuhkan oleh pelajar. Proses identifikasi kebutuhan siswa akan lebih cepat dengan teknologi mechine learning yang tertanam Artifical Intelligence. Semakin banyak data digital yang terhimpun, semakin cerdas pula sistem Artifical Intelligence, contohnya: Google Assistent, Siri, dll. Dengan teknologi-teknologi tersebut, para pelajar disajikan dengan kemudahan dan kecepatan pencarian data, bahkan teknologi tersebut dapat merekomendasikan data yang tadinya tidak terfikirkan oleh mereka. artifical intelligence tidak hanya menyajikan data mentah, namun juga data yang sudah diolah menjadi data sangat informatif disesuaikan dengan kebutuhan penggunanya Pemanfaatan tiga teknologi diatas yaitu Artificial Intelligence, IoT dan Augmented 
Reality diharapkan bisa menciptakan lulusan yang berkualitas dan memiliki kompetensi yang siap pakai di dunia industri (Munanda, 2019).

\section{Peran Bahasa Arab Dalam Pendidikan di Indonesia di Era Society 5.0}

Perkembangan bahasa Arab di indonesia saat ini sangat bagus. Bahasa Arab sudah menjadi trend generasi kekinian di Indonesia. Disamping bahasa Arab adalah bagian dari Agama Islam, bahasa Arab sudah menjadi konsumsi publik untuk urusan dunia dan misi tertentu. Bahasa Arab tidak hanya dipelajari oleh orang muslim, namun juga sudah banyak dipelajari oleh non-muslim. Ini artinya adalah bahasa Arab merupakan bahsa yang selalu unik di pelajari dan sangat bermanfaat. Bahasa Arab adalah bahasa yang tak lekang oleh waktu atau terhapus oleh waktu, karena terus berkembang dan dinamis untuk dikaji menjadi ilmu pengetahuan dan kunci peradaban keilmuan. Di Indonesia bahasa Arab dipelajari di pesantren dan sekolah.

Pemerintah melalui Kemenag mengembangkan bahasa Arab melalui kurikulum pendidikan agama Islam. Dukungan pemerintah seiring dan selaras dengan menyebarnya bahasa Arab di indonesia. Bahasa Arab juga di pelajari dalam bidang informal lembaga kursus dan pelatihan serta melalui media sosial. Ini membuktikan bahwa bahasa Arab sudah menyatu dengan masyakarat Indonesia dan membentuk kebudayaan baru dengan proses akulturasi antara budaya masyarakat Indonesia dan budaya bahasa Arab. Peran bahasa Arab sangat besar terhadap perkembangan bahasa Indonesia, hal inilah yang menjadikan bahasa Arab digemari oleh masyarakat Indonesia. Perbendaharan kata dan ungkapan yang unik dan sejalan dengan gaya perilaku masyakarat Indonesia yang santun maka bahasa Arab memiliki peran yang sangat penting di Indonesia.

Adapun peran bahasa Arab dalam Pendidikan di Indonesia adalah sebagai berikut:

1. Bahasa Arab sebagai Tools (Alat). Dalam konteks pendidikan bahasa arab berperan sebagai:

a) Bahasa Arab sebagai alat kepentingan Ibadah ( Shalat, haji, umroh dsb)

b) Bahasa Arab sebagai alat untuk memahami kitab suci Al-Quran, Hadist, dan kitab-kitab classic keagamaan

c) Bahasa Arab sebagai alat komunikasi (dengan orang pribumi) atau orang arab

d) Bahasa Arab sebagai alat untuk menulis, membaca (Kaidah Tata Bahasa, Seni Kaligrafi, Khat, surat menyurat dsb)

e) Bahasa Arab sebagai alat diplomasi dan kerjasama dunia internasional (dalam semua bidang)

2. Bahasa Arab sebagai object (Obyek). Dalam konteks pendidikan bahasa arab sebagai materi: 
a) Karena bahasa Arab dinamis seiring pertumbuhan manusia, masyakarat/komunitas maka bahasa arab di pelajari dalam lingkung kajian psiko-sosiolinguistik;

b) Bahasa Arab merupakan rumpun ilmu kebahasaan/linguistik maka bahasa Arab akan selalu bersinggungan dengan bahasa lain. Bahasa Arab memberikan khazanah keilmuan yang selalu berkembang dalam perkembangan kosakata baru, uslub/ungkapan, dan kalimat.

3. Bahasa Arab sebagai Subject (Pelaku/Penggerak)

Dalam hal ini bahasa Arab merupakan pembentuk dan memiliki pengaruh dalam bidang-bidang politik, ekonomi dan pendidikan di Indonesia. Eksistensi bahasa Arab sebagai bagian dari Islam menjadikan posisi bahasa Arab menjadi penyempurna bahasa Indonesia serta menjadi pembentuk komunitas sosial masyarakat Indonesia pecinta bahasa Arab. Bahasa Arab juga menjadi bidang utama yang ikut membangun etika dan perilaku masyakarat di Indonesia menjadi lebih santun dan agamis, sehingga bisa diterima masyarakat luas di Indonesia karena karakter bahasa Arab yang membangun semangat hidup, religious, sakral, dan penuh optimisme menjadikan bahasa Arab membaur dengan masyarakat dan di gemari. Di saping itu, bahasa Arab menjadi alat utama pemerintah untuk urusan politik dengan negara Timur Tengah khususnya dengan Saudi Arabia untuk urusan Haji, Umroh, dan dunia pertambangan serta perminyakan. Tidak cukup itu bahwa ternyata bahasa Arab juga memiliki dampak penting pada bidang perekonomian dan komoditi bahan-bahan perdagangan seperti makanan dan pakaian. Banyak makanan-makanan orang Aran serta model-model pakaian ala Arab menjadi konsumsi masyarakat Indonesia. Ini merupakan hal penting di Era Society 5.0 saat ini di Indonesia.

4. Bahasa Arab untuk Misi khusus

Bahasa Arab juga memberikan dampak penting bagi masyakarat Indonesia dalam hal-hal khusus. Terutama dalam bidang penelitian, bahwa masyarakat Indonesia memiliki program untuk membuat wisata halal (syar'i) yang mana nantinya ini menjadi wisata bagi para turis dari timur tengah sehingga mereka menyenangi dan berminat untuk datang ke Indonesia. Bahasa Arab untuk kebutuhan juga berepengaruh pada dunia pekerjaan (lembaga kursus, pelatihan, kajian baik dalam organisasi maupun medsos), Bahasa Arab menjadi juga menjadi standar mutu untuk madrasah, pesantren, dan perguruan tinggi (kompetensi standar kebahasaaraban/Toafl dsb) 
Lalu Bagaimana Peran Bahasa Arab Dalam Paradigma Pendidikan Era Society 5.0? Era Society merubah paradigma belajar dan pembelajaran. Apapun model pembelajarannya, apapun medianya, maka bahasa Arab tetap menajdi CENTER kajian dalam pendidikan. Bahasa Arab memiliki Role yang sangat penting dalam Pendidikan sebagai alat dan obyek. Sehingga bahasa Arab bisa memudahkan manusia untuk berinovasi dan mengembangkan karier serta mampu bertahan hidup di masyakarat yang beragam dan kompleks.

\section{KESIMPULAN}

Berdasarkan penjelasan diatas bahwa sesungguhnya bahasa Arab memiliki peran penting bagi pendidikan di Indonesia. Adapun peran itu adalah 1) Bahasa Arab sebagai Tools (Alat), 2) Bahasa Arab sebagai Object (Obyek), 3) Bahasa Arab sebagai Subject (Pelaku/Penggerak), 4) Bahasa Arab untuk Misi khusus. Peran bahasa Arab memberikan energi positif dalam bidang perekonomian, politik, perdagangan yang mna semua ini di awali dari bidang pendidikan bahasa Arab di Indonesia. Maka dari iru bagaimana di Era Society ini bahasa Arab tetap menjadi CENTER untuk dikembangkan di Indonesia sehingga mampu memberikan dampak positif dan signifikan untuk kemajuan masyarakat Indonesia terutama dalam dunia pendidikan.

\section{DAFTAR PUSTAKA}

Aoun, J, Robot-Proof: Higher Education In The Age Of Artificial Intelligence, Us: Mit Press. Bhakti, C. U, (2018).

Deguchi A.C Hirai, H Matsuoka, T. Nakano, K Oshima, M. Tai, and S Tani, Society 5.0, Chapter 1 In Hitachi-University Of Tokyo Laboratory (H.U Tokyo Lab), Society 5.0 A People-Centric Super-Smart Society, Spinger Open 2020, ISBN 978-981-152989-4

Eka Teguh Iman Santosa N, Epistemologi Partisan Pendidikan Liberal, Adabiyah Jurnal Pendidikan Islam Volume 1, Nomor 1, September 2015.

Eli Nastiti F, Aghni Rizqi Ni'mal 'Abdu, Kesiapan Pendidikan Indonesia Menghadapi Era Society 5.0, Edcomtech Volume 5, No 1, April 2020

Government, C. 0, Society 5.0. Japan. Hayashi, H. S. International Standardization For Smarter Society In The Field Of Measurement, Control And Automation. 56th Annual Conference Of The Society Of Instrument And Control Eng. 2017.

Rohim H, Darwanto, Pendidikan Untuk Menyambut Masyarakat 5.0, Prosiding Seminar Nasional Pendidikan Program Pascasarjana Universitas PGRI Palembang, 10 JANUARI 2020. 
Rahmawati M, Ahmad Ruslan, Desvian Bandarsyah, The Era Of Society 5.0 As the Unifacation Of Humans and Tegchnology: A Literature Review On Materialsm and Existentialism, Jurnal Dialektika, vol. 16 No.2 (2021). 